\section{A controvérsia sobre o uso de alimentação 'alternativa' no combate à subnutrição no Brasil}

\section{The policy and politics \\ of alternative food programs in Brazil: analysis of $a$ controversy}

Lea Velho

Pesquisadora do Institute for New Technologies United Nations University,

Keizer Karelplein 19,

6211 TC Maastricht — Holanda

velho@intech.unu.edu

\section{Paulo Velho}

Analista de ciência e tecnologia, Ministério de Ciência e Tecnologia

Brasília - DF Brasil

velho@ige.unicamp.br
VELHO, L. e VELHO, P.: 'A controvérsia sobre o uso de alimentação alternativa no combate à subnutrição no Brasil'.

História, Ciências, Saúde-Manguinhos, Rio de Janeiro, vol. 9(1):125-57, jan.-abr. 2002.

É consensual a urgência de eliminar a subnutrição infantil no Brasil, mas como fazê-lo é motivo de debates. O Programa de Alimentacão Alternativa implementado pela Pastoral da Criança da Confederação Nacional dos Bispos do Brasil (CNBB) e financiado pelo governo federal e organismos internacionais é um exemplo típico de tais controvérsias. Os críticos do programa têm apresentado "evidências científicas" de que existem problemas de ordem nutricional com os produtos utilizados (partes desprezadas de alimentos) no preparo daquele alimento alternativo ou multimistura. Os proponentes do programa, por sua vez, também se utilizam do mesmo instrumental acadêmico para "demonstrar" o valor nutricional dos produtos utilizados.Este artigo é uma reconstrução e análise do conteúdo e contexto desta controvérsia.

PALAVRAS-CHAVE: alimentação alternativa, multimistura, análise de controvérsia, sociologia do conhecimento, combate à fome, desnutrição.

VELHO, L. e VELHO, P.: 'The policy and politics of alternative food programs in Brazil: analysis of a controversy'.

História, Ciências, Saúde-Manguinhos, Rio de Janeiro, vol. 9(1):125-57, Jan.-Apr. 2002

The urgency to solve infant malnutrition in Brazil is undisputed. Policies to achieve that, however, are not consensual. The Alternative Food Program, put forward by the Catholic National Confederation of Brazilian Bishops Children Pastoral with the support of various federal organizations and international agencies, has been the focus of heated debate. Although the initiative per se has much to be praised for, program opponents argue that nutritional problems in food byproducts have been "demonstrated" by scientific research. To counteract their critics, program proponents also point to scientific results that have just as well "demonstrated" the nutritional value of the used products. The present article reconstructs and analyzes the content and context of this controversy.

KEYWORDS: alternative food, multimixture, analysis of controversies, sociology of information, starvation campaign, malnutrition. 


\section{Introdução}

A preconização do uso de partes 'desprezadas' de alimentos sobretudo farelo de arroz e trigo (Fa e Ft), folha de mandioca (Fm) e casca de ovo (Co) - como suplemento alimentar em dietas para recuperação de desnutridos graves e na dieta normal de creches tem caracterizado, no Brasil, uma persistente controvérsia de saúde, que se intensificou nos últimos anos.

A adoção dessa prática ocorre nos planos nacional e local, em creches e hospitais e tem tido como principais vetores instituições como o Conselho Nacional dos Bispos do Brasil (CNBB) — pela Pastoral da Criança $(\mathrm{CNBB} / \mathrm{Pc})$ - e o Fundo das Nações Unidas para a Infância (Unicef/Brasil), além de receber apoio logístico e financeiro da Fundação Banco do Brasil (FBB) e do Instituto Nacional de Alimentação e Nutrição (Inan), do Ministério da Saúde (MS), particularmente na pessoa da médica pediatra e nutróloga Clara Takaki Brandão, idealizadora da alimentação alternativa.

Por outro lado, já há alguns anos vem se construindo uma sólida oposição a essa prática, estruturada em pesquisas e teses de mestrado e doutorado, com resultados divulgados em trabalhos científicos publicados em revistas da área de nutrição, apresentados em congressos, em circulares distribuídas para agentes e instituições governamentais — alguns deles com o apoio de médicos, cientistas, pesquisadores e associações de classe.

Embora surjam no Brasil, a cada momento, incontáveis controvérsias técnicas nas diferentes áreas do conhecimento — relevantes para a tomada de decisão em políticas públicas —, são raríssimos os casos de estudo dessas controvérsias. O objetivo do presente artigo é fazer uma análise sociológica dessa controvérsia específica.

\section{Análise de controvérsias}

Durante a década de 1970, houve um rápido crescimento das pesquisas sociológicas que procuravam entender as bases sociais do comportamento da comunidade científica e da formação e evolução das idéias dessa comunidade, adotando vários enfoques teóricos e metodológicos, preocupados em evidenciar o caráter contingencial do processo social de construção do conhecimento científico (Mulkay et al., 1983).

A análise das controvérsias técnicas e científicas ganhou destaque nesse contexto, pois é mais fácil identificar as influências sociais (interesses e valores) sobre o conteúdo do conhecimento em situações de disputa do que nas de consenso. Assim, a resistência dos cientistas à inovação e as lutas entre grupos ortodoxos e heterodoxos atuando na ciência e competindo em um mesmo sistema de recompensas científicas passaram a ser um locus privilegiado para o entendimento da construção do 
conhecimento (Webster, 1991). Foi sobretudo com Nelkin (1971) e Mazur (1973) que começaram a se desenvolver com maior intensidade os estudos de controvérsias. Esses autores perceberam que o enfoque permitiria entender a maneira pela qual o status do conhecimento científico dependia de negociações e debates entre as partes interessadas, envolvendo diferentes segmentos da sociedade.

Controvérsia (McMullin, 1987) refere-se a uma disputa, uma discussão ou um debate regular entre indivíduos ou grupos de indivíduos sobre um assunto de interesse comum. As disputas podem envolver temas variados, apresentando características peculiares em função do objeto de discussão. A própria definição do que é uma controvérsia científica é motivo de debate. Para alguns autores, uma controvérsia científica em essência preocupa-se com uma questão de crença, em que cada parte envolvida argumenta que a outra está errada e arroga-se os melhores argumentos. Para haver controvérsia, deve existir um desacordo continuado, além de uma troca pública - oral ou escrita - de argumentos e contra-argumentos, para que qualquer um que nela se envolva ou por ela se interesse possa julgar os méritos do caso.

Para outros, ela seria uma questão de crença, mas um fenômeno social, não podendo "ser reduzida a uma categoria meramente lógica — à existência de proposições contrárias ... e nem a uma categoria meramente psicológica ou mesmo cognitiva - à existência de crenças contrárias" (Giere, 1987, pp. 126-7). Usando conceitos emprestados das ciências sociais, os estudos mais recentes sobre controvérsia têm procurado analisar e entender padrões mais gerais sobre os debates envolvendo ciência e tecnologia (C\&T). Uma tentativa dessas análises mais gerais é entender os padrões de comportamento observados entre vários tipos de participantes das controvérsias, particularmente entre os cientistas.

Apesar de apresentar similaridades com qualquer outro tipo de controvérsia, as controvérsias técnicas e científicas possuem algumas características próprias. Por exemplo: algum produto ou processo de C\&T deve ser o ponto focal da disputa; pelo menos um dos participantes principais deve ser qualificado como experto (Mazur, 1981, p. 10), tecnólogo ou cientista; finalmente, esses expertos devem estar em lados opostos da controvérsia. Nelkin (1984b, pp. 9-10) lembra-nos de que "as controvérsias acontecem sobre praticamente todos os aspectos da ciência e tecnologia a partir do momento em que as decisões que eram definidas como técnicas (ou seja, pertencentes ao domínio dos expertos) tornam-se questões políticas".

É predominante a utilização de estudos de caso para examinar controvérsias técnicas, "porque esse enfoque propicia uma maior riqueza de detalhes sobre características particulares da controvérsia" (Markle e Petersen, 1981, p. 25). À medida que se analisa uma controvérsia, podem-se obter "maneiras eficientes de identificar e avaliar os problemas 
e vantagens de determinadas tecnologias, o que nem sempre é evidente" (Mazur, 1981, p. 9). Um amplo espectro de benefícios pode advir desse tipo de análise. Para Nelkin (1984a, pp. 7, 8, grifo dos autores),

os detalhes das controvérsias podem fornecer a quem as estuda
a compreensão do tipo de raciocínio que motiva as agências
públicas, agentes do governo, cientistas e grupos de protesto.
Esses detalhes podem proporcionar um entendimento realista
das políticas de ciência e tecnologia, seu contexto sociopolítico
e seus impactos. Eles podem realçar as contradições sociais
inerentes de várias decisões na área da ciência e tecnologia e
dos problemas de se desenvolverempolíticas públicas na ausência
de um acordo comum sobre os riscos potenciais dessas políticas.

Segundo a autora, a dinâmica das controvérsias pode revelar “... interesses especiais, preocupações relevantes e suposições implícitas dos vários atores" envolvidos e, visto da perspectiva de um modelo de disputa na sociedade, "o estudo de controvérsias pode se tornar uma ferramenta importante no entendimento dos conflitos e mudanças sociais". Além disso, as controvérsias permitem identificar algumas deficiências das partes envolvidas no debate, como, por exemplo, a falta de informação mais acurada sobre o assunto em discussão; a inexistência de canais apropriados para o encaminhamento de reivindicações pertinentes ao tema em debate; uma eventual falta de representatividade da comunidade que, de alguma forma, deverá ser atingida pelas políticas propostas.

Isso indica, portanto, que estudos de caso, a partir da análise de controvérsias técnico-científicas específicas, podem ressaltar de maneira clara os pontos de interação entre os vários segmentos da sociedade com a C\&T, permitindo a observação, o estudo e o entendimento dessas interações (Giere, 1987).

Seja qual for o enfoque, a análise de controvérsias pode ser vista como ferramenta importante para 'decifrar' os aspectos intangíveis dos contendores, para informar os atores envolvidos na disputa. A utilização dos resultados da análise é importante para reduzir o nível de incertezas associado ao processo de tomada de decisão. Alguns autores sugerem que uma das principais revelações dos estudos de controvérsia "é o uso que as partes oponentes fazem de informações e conhecimentos conflitantes". Cada qual interpreta as informações à sua própria maneira. Daí, "o primeiro passo para entender as controvérsias técnicas é compreender as forças que geram essas informações e conhecimentos conflitantes" (Del Sesto, 1983, p. 396).

Vários conceitos da sociologia do conhecimento científico têm se incorporado ao repertório dos analistas, permitindo uma diversificação de enfoques. Martin (1988), por exemplo, analisando a controvérsia 
sobre fluoridização de água nos Estados Unidos, testou dois enfoques diferentes, o de análise de recursos e o de análise estrutural. Sua conclusão foi pela complementaridade de ambos. Quando se utiliza o conceito de recurso, diferentes valores são trazidos para a disputa e considerados como 'recursos' ou 'ferramentas', como, por exemplo, suposições e reivindicações sobre conhecimento e autoridade, metodologias, controle sobre publicações, auxílios a pesquisa etc.

A retórica usada em conversações entre os cientistas e em publicações sobre o assunto acaba sendo utilizada como importante recurso no processo de convencimento da outra parte. Palavras e frases atuam de modo decisivo para aqueles que buscam, em suas associações e corporações, ou entre cientistas de notória visibilidade entre seus pares, argumentos e 'evidências' que permitam a tomada de posição em relação ao debate. O padrão de retórica utilizado pelas partes envolvidas na controvérsia não difere substancialmente. É importante para ambas substanciar suas conclusões da maneira mais apropriada aos compromissos sociais. Para isso, as reivindicações de cada lado passam a ser fundamentadas de maneira a fortalecer sua própria posição e fragi-lizar a do oponente, à semelhança do que ocorre em qualquer negociação informal dentro da própria comunidade científica (Mulkay, 1985).

A autoridade científica é indicada como um recurso relevante nos debates. Por exemplo, os participantes 'passivos' não examinam, em qualquer nível de detalhe, tanto da perspectiva científica como ética, as questões técnicas levantadas por pessoas e organizações em que confiam e que estão ativamente envolvidas na discussão. O endosso que é dado pelos associados às corporações representativas baseia-se exclusivamente no trabalho dos expertos. Esse modelo de 'pirâmide invertida' de apoio é característico de várias controvérsias.

As controvérsias que envolvem disputas científicas sobre tomadas de decisão política apresentam ainda maior grau de complexidade. Estas disputas compreendem níveis mais acurados de informação científica, que, na maioria dos casos, estão além da compreensão dos tomadores de decisão, cujo recurso é recorrer aos especialistas da área. Mas os especialistas acabam desempenhando papel ambivalente: são indispensáveis à resolução da controvérsia, mas podem ser suspeitos, em função dos interesses que defendem.

O conhecimento técnico dos cientistas acaba sendo considerado uma fonte de poder na resolução das controvérsias, pois a ciência teria capacidade de legitimar e certificar algumas descrições da 'realidade'. Nesse caso, interesses conflitantes estariam de fora dos debates sobre alternativas técnicas disponíveis, considerando-se somente a eficiência relativa dos vários enfoques para resolver uma questão imediata. Assim, o conhecimento científico como expertise seria usado como base racional para o planejamento e a tomada de decisões políticas.

À medida que se percebe a crescente importância que conhecimento e expertise vêm assumindo nas disputas científico- 
${ }^{1}$ Utilizando modelos de 'interesse social' em conjunção com 'análise de controvérsias', alguns autores procuram elucidar de que forma as pretensões de conhecimento dos cientistas se relacionam com seus compromissos sociais. A partir desses estudos, é possível afirmar que a análise sociológica do conhecimento científico propicia melhor entendimento das interações entre avaliações de risco e seu contexto social, cultural e político (Abraham, 1993). tecnológicas, o próprio acesso e o domínio desses conhecimentos têm se tornado uma fonte de conflito. Nelkin (1975) considera que as complexidades das tomadas de decisões públicas têm exigido conhecimento e expertise cada vez mais especializados, o que acaba por atribuir um poder considerável àqueles que controlam esses tipos de conhecimento.

Assim, a importância crescente da informação técnica especializada acaba orientando os pesquisadores e cientistas para se dedicarem a trabalhos que envolvem temas controvertidos. É o que sugere Mazur (1973), ao comentar que as atividades dos cientistas são afetadas pelos contextos políticos das controvérsias. Também são afetadas as maneiras como os resultados das descobertas são apresentados, o que pode influenciar sobremaneira algumas decisões.

Apesar das normas de neutralidade política, segundo Mazur (apud Nelkin, 1975), os cientistas comportam-se como outra pessoa qualquer quando se engajam em disputas, polarizando seus pontos de vista. Isso pode comprometer os valores do aconselhamento científico, tornando-o questionável. Procurando entender o impacto político do aconselhamento especializado em dois casos de conflito 'técnico', Nelkin sugere algumas proposições que poderiam ser generalizadas para outras controvérsias que envolvem expertise técnica conflitante. São elas: os proponentes de políticas procuram expertises para legitimar seus planos, usando seu controle sobre o conhecimento técnico para justificar sua autonomia; o aconselhamento do experto pode ajudar a esclarecer alguns gargalos técnicos, mas, ao mesmo tempo, provavelmente aumenta o conflito, sobretudo quando o conhecimento especializado é disponível para aqueles que propõem — ou rejeitam - determinada técnica, tecnologia etc.; a medida de aceitação do aconselhamento técnico depende mais do quanto ele reforça as posições existentes do que de sua validade e da competência do experto. Finalmente, o papel dos expertos parece ser similar e independente da área em que eles atuam.

Os especialistas, entretanto, não raras vezes defendem interesses específicos, podendo representar, por exemplo, uma associação particular, uma agência governamental ou uma organização nãogovernamental (ONG) (Mazur, 1987; Mulkay, 1985, pp. 113-4). ${ }^{1}$ Acredita-se que o papel dos cientistas (como expertos), a longo prazo, não é relevante para o encerramento de controvérsias técnicocientíficas, visto que elas na verdade são resultado da confluência de forças de natureza "social, política e econômica, que usam o processo do debate sobre assuntos técnicos para atingir seus próprios objetivos" (Allen, 1987, p. 170). Mesmo nos debates em que as questões explicitadas são eminentemente técnicas e nas quais os expertos envolvidos reafirmam o importante papel do conhecimento técnico-científico para a sua resolução, as incertezas (técnicocientíficas) não raramente passam a ser apontadas como responsáveis 
pela controvérsia. Para alguns desses pesquisadores, "se nós tivéssemos mais informações, os desacordos desapareceriam" (Campbell, 1985, p. 429).

Campbell considera ilusória essa solução para os conflitos sociais. Para ele, como a autoridade do cientista, como experto, repousa sobre conhecimento e certezas, a credibilidade e a importância desses cientistas estariam sendo comprometidas pelas questões de incerteza. Além disso, a incerteza não é causadora de controvérsias e julgamentos quando se considera que a quantidade e a qualidade de conhecimento são objetos de negociação social. Para Campbell (op. cit., p. 430), incerteza na ciência é uma questão para negociação, decisão e discussão. Em suas palavras, "cientistas não podem divergir (em suas opiniões) por uma falta de fatos que forçaria um julgamento, pois a existência de incertezas é o resultado de interpretação e negociação contínuas".

Entre os pontos indicados como relevantes por Campbell (idem, p. 449) em sua discussão sobre a incerteza como ação simbólica em disputas entre expertos, dois são importantes para nossa discussão: o tema incerteza (nas controvérsias), mais do que alguma coisa que causa discussão, é um elemento estratégico de argumentação; e os argumentos sobre incerteza não necessariamente enfraquecem a credibilidade do conhecimento científico especializado nem a efetividade política do cientista como experto.

Uma das áreas do conhecimento científico que tem se mostrado particularmente profícua na geração de controvérsias e na qual a confluência de forças de diferentes naturezas se manifesta de maneira bastante intensa parece ser a medicina contemporânea. O status epistemológico privilegiado dessa área do conhecimento é objeto de críticas que têm se intensificado recentemente. As críticas têm origens distintas, e Richards (1988, p. 653) identifica algumas delas como originárias dos antropólogos sociais e historiadores que têm explorado particularmente a contingência cultural daquele conhecimento. Os médicos sociólogos constituiriam uma segunda fonte de críticas, ao descrever a medicina como "uma instituição de controle social e o locus de luta de poder profissional pela autoridade cognitiva e controle". Finalmente, mas não de menor importância, estariam os críticos que têm questionado a "autonomia e eficácia de tal conhecimento".

A sociologia do conhecimento pós-kuhniana sinaliza no sentido de uma releitura da visão convencional que se tinha do conhecimento científico como um corpo de conhecimentos neutros, tanto em seus aspectos valorativos quanto objetivos. A medicina moderna é uma das áreas da ciência que tem permanecido praticamente à margem desse processo de revisão, embora seja uma das mais profícuas no que se refere ao número de controvérsias e disputas, de inegável valor para a análise sociológica e de imensa relevância para a tomada de decisão em políticas públicas. 
O fato de existirem poucos estudos empíricos que analisem e avaliem a produção do conhecimento médico contemporâneo acaba por reforçar a visão que privilegia o caráter epistemológico especial desse conhecimento. Isso dificulta o trabalho dos críticos, por privá-los de um suporte empírico essencial para a sustentação de suas posições. Estes críticos afirmam que interesses econômicos e sociais desempenham papéis fundamentais na formulação da teoria e da prática médica. Assim, consideram incorreta qualquer tentativa de avaliar o conhecimento médico sem a ponderação desses interesses.

Algumas das controvérsias analisadas na área médica mostram que procedimentos experimentais (testes clínicos mais rigorosos) e regras objetivas não são suficientes para resolver disputas sobre "fatos". Sempre que ocorre a "resolução" de uma controvérsia ou disputa nessa área, a resolução é alcançada a partir de pressões das comunidades envolvidas em seu julgamento, incluindo "não apenas os conhecimentos aceitos pela comunidade envolvida, mas também os interesses e objetivos sociais que esses conhecimentos incorporam" (Richards, 1988, p. 654).

No encerramento político da controvérsia sobre o uso da vitamina C como alternativa para o tratamento de algumas formas de câncer, Richards aponta evidências de que a avaliação terapêutica é um processo eminentemente social e político. A conclusão de Abraham (1993, p. 428), em seu estudo sobre a avaliação de riscos do uso de benoxaprofen como substância carcinogênica nos Estados Unidos e no Reino Unido, segue a mesma linha. Segundo ele, "as evidências apresentadas sugerem fortemente que interesses comerciais e corporativos podem ter influenciado as avaliações de risco sobre as propriedades carcinogênicas do benoxaprofen feitas pelas indústrias e instituições governamentais".

O papel fundamental que as estruturas sociais mais amplas desempenham na resolução de uma controvérsia torna-se evidente também no estudo comparativo desenvolvido por Gillespie et alii (1979) sobre o potencial carcinogênico dos pesticidas clorados e no que McCrea et al. (1984) realizaram sobre o uso terapêutico do estrogênio nos mesmos países. As avaliações conflitantes, nesses casos, são atribuídas a diferentes fatores sociais, políticos e econômicos prevalecentes não apenas nos diferentes países estudados como dentro de um mesmo país.

É à luz do referencial conceitual exposto anteriormente que analisaremos, a seguir, os debates envolvendo a recomendação e o uso de subprodutos de alimentos preconizados sobretudo pela Pastoral da Criança, em seus programas emergenciais de combate à fome.

\section{A alimentação alternativa e seus proponentes}

O Brasil ocupa posição desconfortável no ranking mundial de países com fraco desempenho na área social não apenas nos setores de educação e habitação, mas também como um dos países que alimenta mal os seus cidadãos. Dados recentes, citados por Nogara (1994), indicam que a 
${ }^{2}$ Diferentes índices são usados para calcular diferentes categorias de desnutrição, conseqüências diferentes e procedimentos diferenciados para solucioná-los. desnutrição energético-protéica continua sendo um problema grave de saúde pública no Brasil. Grosso modo, 31\% das crianças brasileiras menores de cinco anos apresentam desnutrição, independentemente do grau considerado, ${ }^{2}$ sendo que essa desnutrição já é alta nos seis primeiros meses de vida ( $21 \%$ dos bebês).

No que se refere às diferentes categorias, há, no Brasil, desnutrição crônica, dada pela relação entre altura e idade, com uma prevalência de $15,4 \%$, contra um esperado de não mais de 3\%. A proporção elevada dessa forma de desnutrição está diretamente associada à mortalidade infantil, embora, obviamente, as estratégias de combate à desnutrição devam ter como objetivo a eliminação de qualquer uma de suas formas. Têm-se sugerido diferentes maneiras de combater a desnutrição. A mais conhecida é a distribuição do leite, que recebe apoio governamental, através de subsídios. Mas outras iniciativas disseminamse pelo Brasil todo e constituem o elemento central da controvérsia aqui analisada. São as "formas alternativas, simplificadas e de baixo custo" de alimentação, que se caracterizam pelo uso de partes não convencionais dos alimentos, ${ }^{3}$ com destaque para o $\mathrm{Fa}$ ou Ft, as sobras de vegetais, a Fm e a Co.

Denominadas de modo genérico como alimentação alternativa (AA), essas iniciativas, segundo Beausset (1992), devem preencher vários requisitos: o maior número possível de alimentos deve ser usado em cada refeição; todas as partes possíveis do alimento devem ser aproveitadas, sem desperdício; deve-se dar preferência a alimentos disponíveis segundo região e época e aos de menor custo; o alto conteúdo de micronutrientes nesses alimentos deve prover um suplemento importante para a saúde; toda pessoa, para preservar sua dignidade, deve prover, por si própria, sua alimentação e deve tomar decisões informada sobre o alimento que vai consumir.

No princípio, o conceito de AA era utilizado "para grupos de maior risco de deficiências nutricionais, como desnutrição energético-protéica, anemia e hipovitaminosas" (idem, ibidem, p. 1). Embora, ainda hoje, a população alvo ainda se constitua de indivíduos com as características já descritas, essa alimentação tem sido promovida também como dieta saudável para toda população, no sentido de prevenir deficiências de fibras, minerais e vitaminas.

Shrimpton (1984) localiza e relata as origens da utilização da AA, em meados da década de 1970, em Santarém (PA), quando os médicos Clara Takaki Brandão e Rubens Brandão, que já vinham trabalhando com ações básicas de saúde em diversas cidades do país, constataram um elevado grau de prevalência de desnutrição entre as crianças de zero a cinco anos, naquele município. Com um grupo de pessoas, eles fundaram a Sociedade de Estudos e Aproveitamento dos Recursos da Amazônia (Seara), com um elenco de objetivos gerais que incluía a minimização das graves conseqüências da desnutrição na primeira infância. 
${ }^{4}$ Iremos nos concentrar prioritariamente nesse componente da MM, pois o $\mathrm{Fa}$ acaba sendo o nó górdio do debate em questão.
Segundo seu próprio relato, a dra. Brandão (1996) procurou resgatar, através da história oral contada pelos idosos da região, os hábitos alimentares de 'antigamente', quando a taxa de mortalidade infantil não era tão alta como as atuais. A médica concluiu que uma dieta adequada seria um dos fatores decisivos para a reversão do quadro de desnutrição observado no município, e que, segundo seus conhecimentos, mantinha estreita correlação com o alto índice de mortalidade infantil.

Em visita a colônias japonesas da mesma região, a dra. Brandão observou um alto consumo de farelo de arroz pela comunidade. Constatando, a partir de consultas a tabelas nutricionais, a alta concentração de minerais e vitaminas no farelo, elaborou um cardápio com as 'riquezas regionais', às quais incorporava aquele produto. Após testar a mistura em casa, junto com as monitoras de saúde, passou a implementar o cardápio nas 13 creches que atendiam, em conjunto, 390 crianças. Após três dias de consumo da dieta, Clara Brandão observou uma redução drástica de diarréia entre as crianças. Para ela, a introdução do farelo de arroz na dieta composta de alimentos locais foi crucial para a obtenção dos resultados de recuperação de desnutridos, mais do que todas as outras ações básicas de saúde que já vinham sendo implementadas. ${ }^{4}$

Os resultados da experiência piloto desenvolvida pela Seara e pelos dois médicos foram apresentados em seis comunicações, no XXIII Congresso Brasileiro de Pediatria (Brandão et al., 1983a, 1983b, 1983c, 1983d, 1983e, 1983f), e receberam o prêmio Álvaro Bahia. O reconhecimento concedido pela Sociedade Brasileira de Pediatria (SBP) e pela Sociedade de Pediatria da Bahia deu ao programa da Seara maior visibilidade. Ele passou a receber visitas de vários consultores do Unicef, culminando com uma avaliação patrocinada por aquele órgão e realizada por um de seus consultores, Roger Shrimpton (1984, p. 370). Com relação ao impacto nutricional do programa, o relatório do Unicef foi extremamente favorável, ressaltando, no entanto que, das quase mil crianças atendidas pela Seara em suas creches, apenas 232 fichas antropométricas puderam ser analisadas, porque só elas continham os dados necessários.

Para essas crianças, após se compararem as freqüências de desnutrição de I, II e III graus, antes e depois da permanência por um determinado período no casulo (as creches), a melhora no estado nutricional foi significativa. Para o consultor, "todas as crianças cresceram mais do que era esperado para sua idade", sendo que "essa recuperação foi mais acentuada nas crianças que tinham desnutrição de grau II e III", observando ainda que "a taxa de crescimento das crianças com grau III de desnutrição foi significativamente maior do que a das crianças normais".

Em 1983, a CNBB criou no Brasil a Pastoral da Criança. Trabalhando na mesma linha que a dra. Brandão, a dra. Zilda Arns, criadora e coordenadora nacional da Pastoral, convenceu-se dos resultados da 
utilização da multimistura (MM) e do Fa, passando a difundir seu uso entre as famílias que tinham filhos freqüentando as creches mantidas pela Pastoral. O envolvimento do Unicef com a divulgação dessa prática foi direta, inclusive financiando o plantio de mandioca para posterior utilização das folhas (Fm), como pó a ser acrescentado na MM. O Unicef/Fortaleza (1994, grifo dos autores), em avaliação recente da AA e do papel das instituições em sua divulgação, concluiu que

No Brasil, a proposta conhecida como 'alimentação alternativa' está contribuindo para diminuir o risco nutricional de crianças e gestantes, pelo fato de incluir práticas alimentares em grande parte baseadas em conhecimentos científicos consolidados e pela sua integração com a promoção de ações básicas de saúde de comprovada eficácia e com iniciativas que favorecem a dedicação de atenção e carinho para as crianças.

A partir da utilização da MM pela Pastoral da Criança, a divulgação dessa prática ganhou dimensões nacionais (CNBB/PC, 1996), inclusive por parte do governo (Salomon, 1996). A força da disseminação da idéia desse programa foi surpreendente.

No final da década de 1980 e início da de 1990, várias instituições, entre elas a Fundação Banco do Brasil (FBB), passaram a colaborar na divulgação da prática da AA, com o financiamento de Receituários Culinários, reeditados periodicamente (FBB, 1996, 1993) e distribuídos pela vasta rede de agências do Banco do Brasil no território nacional. A multiplicação da idéia ocorreu também por meio de folhetos publicados pela administração de diversos e incontáveis municípios brasileiros.

Em 1989, no último ano do governo Sarney, Clara Brandão e seu marido transferiram-se para Brasília, para o Ministério da Saúde, convidados pelo então secretário executivo do ministério, que entendia que o "trabalho de AA tinha que ficar em nível central, e não em nível de periferia". A transferência atuou como um amplificador de suas ações, visto que, como a própria médica reconheceu, "a base institucional foi fundamental, pois me deu um respaldo, e eu passei a me apresentar como um integrante do Ministério da Saúde, o que me abria as portas ... além da oportunidade de viajar" pelo Brasil todo, divulgando suas idéias (Brandão, 1996)

Enquanto se desenvolviam essas ações de divulgação do uso da $\mathrm{MM}$, vinham se realizando alguns trabalhos independentes de pesquisa que procuravam analisar cientificamente o valor nutricional e recuperativo desse produto. Alencar et alii (1991, p. 105) fizeram uma avaliação da composição química do farelo e seu potencial como alimento, concluindo que

O farelo de arroz constitui uma fonte de nutrientes de baixo custo, que pode ser utilizada na complementação da dieta humana, 
melhorando sua qualidade nutricional, sem modificar hábitos alimentares ... o farelo alia valor calórico, proteína de boa qualidade e minerais essenciais ao homem.

A importância do farelo como alimento humano havia sido apontada anteriormente também por Gondim et al. (1995, p. 61). Os autores fizeram uma análise comparativa dos efeitos do uso do Ft (similar ao arroz embora com uma quantidade de fitato menor), concluindo que houve

melhoria do grau nutricional das crianças, ... devido à qualidade de saúde que elas adquiriram com a administração do farelo, deixando de adoecer ou de tomar certos medicamentos (principalmente antibióticos) que retardam o seu ganho pondero-estatural ... e também uma melhora significativa em relação às patologias intercorrentes, como infecções respiratórias agudas, diarréias, problemas de pele, anemias entre outras.

Além desses experimentos construídos especificamente para a avaliação empírica do potencial nutritivo-recuperativo dos Fa e Ft, os proponentes da AA indicavam como evidência de bons resultados da utilização da alimentação o trabalho da Pastoral da Criança com a recuperação nutricional de crianças, gestantes e nutrizes, "numa atuação plenamente exitosa, como confirmam todas as menções e prêmios que honram esta instituição, nacional e internacionalmente" (Rodriguez, 1996, p. 5).

O Inan também vinha se preocupando com a disseminação exponencial da prática de utilização da $\mathrm{MM}$ como suplementação alimentar. Com o objetivo geral de "buscar respostas para questionamentos básicos que surgiram com a utilização por grupos comunitários e algumas instituições desses alimentos (alternativos), o Inan, no cumprimento de suas atribuições", realizou um workshopem Brasília, em 1992. Com o apoio da Organização Pan-Americana de Saúde (Opas), reuniu-se um grupo multiprofissional, na tentativa de buscar esclarecimento para uma série de questões pertinentes à AA (Inan/MS, 1992, pp. 1, 3). O workshop, em suas conclusões gerais, afirmava ser

reconhecido o fator potencial de utilização de algumas alternativas alimentares (farelo de arroz, trigo, folhas verdes escuras) na recuperação e manutenção do estado nutricional de crianças e gestantes, porém os trabalhos existentes ainda não são suficientes para afirmar com segurança o impacto produzido.

Mesmo levando em conta o consenso dos que utilizavam esse tipo de alimentação, os participantes do workshop reiteravam a 
"necessidade de uma avaliação mais minuciosa utilizando-se critérios científicos nos quais os dados sejam obtidos de maneira sistematizada e uniforme, ... utilizando-se indicadores previamente selecionados e coletados por pessoal devidamente qualificado para este fim" (idem, ibidem, grifos dos autores). E listavam pesquisas básicas e clínicas que deveriam ser realizadas para que se diminuísse o grau de incerteza associado à AA.

Quase dois anos mais tarde, em abril de 1994, atendendo a um item das conclusões gerais do workshop, foi criado um grupo de trabalho com o objetivo de "elaborar um relatório com recomendações que representem um consenso de profissionais da área" sobre o tema AA. O grupo tinha como coordenador o presidente do Inan, e como uma de suas integrantes a dra. Clara Takaki Brandão, representando a Secretaria Executiva do Ministério da Saúde.

O documento produzido pelo grupo enalteceu a AA e recomendou a criação imediata de um Programa de Orientação Alimentar para a Saúde, a ser desenvolvido pelo Inan, em articulação com outras instituições e setores, para "estimular e apoiar financeiramente a realização de estudos e pesquisas sobre novas alternativas alimentares". A primeira questão a ser tratada pelo programa seria a inclusão da AA nos programas do Ministério da Saúde, a partir de uma estratégia previamente estabelecida. Recomendava ainda a "oficialização do uso de Fa e Ft para o consumo humano desde que "cumpridas algumas exigências" (Ministério da Saúde, 1994a, p. 8).

O Programa de Orientação Alimentar para a Saúde foi instalado no Inan em setembro de 1994 e integralmente implantado a partir de 1995, tendo como coordenadora a dra. Clara Brandão. No entanto, para alguns pesquisadores da área de nutrição, os resultados favoráveis da MM na recuperação de subnutridos não eram suficientes nem convincentes. Em vista disso, eles propuseram-se a determinar, com rigorosa investigação científica e amplo debate com a comunidade interessada, o 'real' valor das fontes de nutrientes utilizadas na MM, e mais especificamente sua eficiência como provedores de minerais.

\section{A oposição}

Entre as instituições que têm se posicionado enfaticamente contra a utilização da AA está o Conselho Federal de Nutricionistas (CFN) (<http://www.crn2.org.br/crns.htm>). Em setembro de 1990, o CFN já havia elaborado parecer sobre uma publicação de autoria de Clara Brandão (1989), intitulada 'Alimentação alternativa', e apontava, em 11 itens, diversos erros técnicos e conceituais do folheto. Questionava com particular ênfase as "observações empíricas" feitas pela autora sobre a utilização do Fa ou do Ft incorporados à dieta habitual de crianças desnutridas 
"com excelentes resultados". O CFN (1996a, pp. 5, 8, grifos dos autores) ressaltava que os resultados relatados por Brandão

deveriam ser comprovados por pesquisas científicas que validassem o emprego do mencionado farelo para prevenir ou tratar as patologias citadas no texto, antes da divulgação do folheto... (pois) revisando a literatura científica especializada, nada encontramos referente à eficácia do farelo de arroz no controle ou tratamento dos estados patológicos referidos ... e que os resultados expostos poderiam induzir o leitor a não procurar assistência médica para aqueles estados patológicos que, segundo a autora, foram curados ou controlados (diabete) pela ingestão de arroz.

Finalmente, o documento do CFN, com o objetivo "tão-somente de impedir a difusão de informações incorretas sobre alimentação e nutrição e evitar possíveis danos à população", solicitava providências ao ministro da Saúde, "no sentido de que seja sustada a divulgação do folheto 'Alimentação alternativa' para as indispensáveis correções". Em momento algum o documento questionava o caráter das ações propostas. Também não se referia a dois pontos específicos que viriam mais tarde constituir o eixo das críticas aos programas de AA. O primeiro deles é o conceito de biodisponibilidade de nutrientes, e o segundo, as questões relativas à Declaração de Helsinki.

Com relação ao conceito de antinutrientes, o dr. Amaya-Farfán - diretor da Faculdade de Engenharia de Alimentos da Universidade Estadual de Campinas (Unicamp) - e seus colaboradores, com base na bibliografia disponível, afirmavam que, para se proceder a uma avaliação correta do valor biológico da enorme gama de macro e micronutrientes dos alimentos, particularmente o Fa, seria indispensável a determinação paralela de uma série de antinutrientes e contaminantes presentes nesses alimentos. Assim, eles criaram uma linha de pesquisa com o objetivo de conhecer o valor nutritivo 'real' do Fa. Dessas pesquisas resultaram algumas comunicações em congressos (Torin et al., 1994, 1993; Domene et al., 1994), uma dissertação de mestrado (Torin, 1991) e duas teses de doutoramento (Torin, 1996; Domene, 1996). Torin (1991, p. 118, 120) chegava a algumas conclusões, apontando que:

A composição química do farelo de arroz indica que este resíduo é, no mínimo, uma potencial fonte de proteínas, de alguns elementos minerais como $\mathrm{Zn}, \mathrm{Cu}$, Fe e $\mathrm{Mn}$, e particularmente fibras alimentares, (embora) o elevado conteúdo de ácido fítico (seja) um fator que compro-mete a biodisponibilidade dos minerais presentes no farelo de arroz.

Ela concluía também que o farelo de arroz "possui um certo poder recuperativo em ratos em crescimento, previamente 
submetidos a um estresse nutricional com arroz branco", embora "essa capacidade (seja) muito baixa experimentalmente quando comparada com o próprio farelo enriquecido com vitaminas e minerais", e observava, a despeito de algumas observações positivas sobre o valor nutritivo do farelo de arroz, que "o farelo de arroz industrial torrado não é recomendado como substituto de suplementos vitamínicos e/ou mineral completos, nem em casos de alimentação normal nem deficiente. Exceção poderia ser feita na inexistência de complementos completos."

Torin et al. (1994, 1993; Domene et al., 1994) concentraram seus esforços na argumentação de que o Zn seria o elemento cuja biodisponibilidade seria mais afetada no Fa, pelo alto conteúdo de ácido fítico (6\%). No desenvolvimento da controvérsia, o ácido fítico, considerado como antinutriente, se tornaria o principal argumento técnico dos oponentes da AA.

Nogara (1994, pp. 57, 54) teve como principal objetivo identificar a interferência do Fa no estado nutricional de crianças a partir da dosagem de marcadores nutricionais de alta sensibilidade. Apesar de ter "observado um aumento estatisticamente significativo nos níveis de zinco sérico no grupo que recebeu a suplementação com Fa", a autora concluiu que "a suplementação alimentar com farelo de arroz não interferiu no estado nutricional deste grupo de crianças", pelo menos durante o período de cinco meses que durou o experimento. Para ela o acréscimo nos níveis de zinco pode, "em parte, ser atribuído ao Fa", mas reconhecia que os resultados "contrastam com estudos que referem uma diminuição da biodisponibilidade do zinco nos alimentos ricos em fitatos, como o Fa".

Para o dr. Amaya-Farfán (1996), o aumento de zinco, contudo, não provinha necessariamente do que fora absorvido pelo intestino. Segundo suas palavras, o aumento de Zn sérico

é apenas um fato que não deve ser considerado isoladamente. $\mathrm{O}$ Zn sérico não se origina necessa-riamente do que foi absorvido pelo intestino, pois o $\mathrm{Zn}$, como qualquer outro nutriente, é o resultado de um equilíbrio (entre) o que é absorvido e o que o organismo tem estocado, sendo que o aumento do $\mathrm{Zn}$ no soro pode estar sendo importado de algum outro órgão. Quer dizer que isso (o aumento de Zn sérico no sangue) pode ser usado como mais um ponto desfavorável (ao uso do Fa), dependendo de resultados futuros.

Em sua tese de doutoramento, Torin (1996, p. 79), procurando desenvolver uma técnica para determinação comparativa da mineralização óssea, elegeu uma dieta à base de farelo de arroz industrial como fonte de minerais. Embora o objetivo específico do trabalho fosse testar uma nova técnica — processamento de imagens radiográficas - na determinação comparativa da mineralização óssea, sua primeira 
conclusão referia-se à qualidade do Fa como fonte de nutriente e os seus efeitos - negativos - no crescimento e na composição mineral do osso do modelo biológico experimentado, o rato. A autora não deixava dúvidas com relação a isso, quando concluía que "o consumo de dieta à base de farelo de arroz causa efeitos claramente prejudiciais ao crescimento e composição mineral do osso do rato".

Avaliando os efeitos da suplementação do Fa com os minerais zinco, ferro, cobre e cálcio sobre os indicadores de crescimento e deposição hepática de zinco em ratos, Domene (1996, p. 79) concluía que "a necessidade de adicionar minerais a uma dieta de farelo de arroz para melhorar suas propriedades nutricionais invalida as propostas de utilizar este subproduto como fonte de minerais para o rato e provavelmente também para o homem".

Para os oponentes da AA, portanto, em função das 'evidências científicas' obtidas em uma série de pesquisas conduzidas dentro do rigor acadêmico, as argumentações contrárias ao uso da AA pareciam centrar-se particularmente na questão do ácido fítico contido nos farelos (de arroz ou trigo) e nas sementes trituradas que compõem a MM.

E foi com base sobretudo na argumentação sobre a drasticidade do ácido fítico como antinutriente que esses mesmos pesquisadores, todos da Unicamp e integrados aos trabalhos do dr. Amaya-Farfán, deflagraram uma campanha de "esclarecimento" entre seus pares. A campanha pretendia alertar para os perigos da preconização do consumo de uma dieta composta de elementos cuja eficiência era questionada pelos resultados das pesquisas por eles realizadas. Assim, o dr. Amaya-Farfán e seus colaboradores criaram um informe técnico (IT), com ampla circulação entre os pesquisadores que trabalhavam com a questão da nutrição infantil.

O IT, datado de julho de 1994, com três páginas e impresso em papel timbrado da Unicamp, trazia 19 citações bibliográficas para respaldar seu enunciado. Dentre elas, 18 eram de publicações interna-cionais. No informe, os autores concentravam-se particularmente na questão do ácido fítico. Além disso, os médicos Jaime Amaya-Farfán e Hilda R. Torin, ambos da FEA/Unicamp, e Semiramis M. A. Domene, da Faculdade de Ciências Médicas da Pontifícia Universidade Católica de Campinas (Puccamp) consolidavam suas posições contrárias à utilização da MM composta de Fa, procurando desqualificar seu uso como suplemento alimentar. Para isso, os autores alegavam que uma série de outros fatores deviam ser considerados antes de se propor a utilização dos componentes da MM, especificamente o Fa, elemento básico da AA.

Eles criticavam ainda as condições em que o Fa é obtido, levando a uma alta contaminação por fungos toxicogênicos, como, por exemplo, a aflatoxina. Outros subprodutos, como a Fm, eram objeto de críticas, em função do alto teor de glicosídios cianogênicos, de difícil eliminação e alto potencial tóxico para quem 
o consome. Em momento algum do IT, ressalvava-se que os resultados apresentados eram apenas 'parciais'.

O documento evocava também os princípios básicos da Declaração de Helsinki, de 1964, que estariam sendo desrespeitados, quando se submetia um imenso contingente de crianças a uma experimentação com alimentos de eficiência não comprovada sem antes testá-lo em modelos biológicos ou sem respeitar os protocolos de experimentação científica com humanos. Os autores afirmavam que não se conhecia ainda a "composição química da MM (nem) o caráter bioquímico-nutricional acerca dos efeitos resultantes de interações dos seus constituintes". Sem esses conhecimentos, diziam eles, "não é aceitável sua introdução como alimento, principalmente para crianças, pois não existem informações a respeito dos possíveis efeitos a médio e longo prazo decorrentes desta prática" (Torin et al., 1994, p .3).

Outro objeto de críticas era o controle de qualidade sanitária do Fa e de outros componentes da MM. Para os autores do IT, esse aspecto devia ser levado em conta, pois análises (bromatológicas) do produto indicavam a presença de sujidades inaceitáveis em um produto a ser consumido pela população. Diante disso, concluíam que consideravam prematura a utilização do farelo em programas de alimentação infantil em larga escala.

O documento foi encaminhado a pessoas e instituições proeminentes na área de nutrição humana, deflagrando um amplo processo de oposição à utilização da MM, como se pode avaliar por algumas das respostas. O dr. Luís Trugo (1994, grifo dos autores), professor do Laboratório de Bioquímica Nutricional da Universidade Federal do Rio de Janeiro (UFRJ), escreveu em sua carta-resposta ao IT: "Especificamente sobre o uso do farelo de arroz, concordamos com a prematuridade de preconizar-se o seu uso indiscriminado, 'sem o necessário aval de investigação científica'." Os professores do curso de nutrição da Faculdade de Ciências Médicas da Puccamp também manifestaram apoio ao informe, concordando que "a utilização de subprodutos industriais não pode ser feita 'sem a pesquisa aprofundada' das possíveis implicações dos mesmos para a saúde da população" (Faculdade de Ciências Médicas-Puccamp, 1994, grifo dos autores).

O dr. Dutra de Oliveira (1994), professor da Faculdade de Medicina de Ribeirão Preto, e um dos pesquisadores da área de nutrição de grande visibilidade entre seus pares, embora reconhecesse que os "dados de conhecimento popular ... podem ter valor real e devem ser melhor estudados", ressaltava a necessidade dos "devidos e cuidadosos estudos científicos", antes de serem utilizados em larga escala pela população. Além disso, lamentava "que leigos ... passaram a pontificar sobre os nossos problemas de alimentação e nutrição, (enquanto), por outro lado, a comunidade 
científica da área de ciências nutricionais tem sido colocada no ostracismo".

$\mathrm{Na}$ mesma linha, mas de maneira mais ortodoxa, manifestou-se a International Society of Pediatric Nutrition (ISPN), através de seu diretor executivo, o dr. Fernando José de Nóbrega. Em seu nome e no da ISPN, ele endossava as conclusões do IT, e, tendo tomado a iniciativa de levar o documento à reunião do Comitê de Nutrição da Sociedade Brasileira de Pediatria (SBP) — da qual era presidente —, relatava também a posição daquele comitê, que, entre outros pontos, concluía por "apoiar, frente aos dados fornecidos por V. Sas., suas conclusões; propugnar pela não realização de mais trabalhos nessa área já que os conhecimentos que recebemos não só do seu grupo, mas de outros, é suficiente para avaliar os efeitos da utilização do farelo de arroz" (ISPN, 1994).

O Centro de Referência da Saúde da Mulher, da Secretaria de Saúde do Estado de São Paulo (SSESP), concordava com "as colocações emitidas no informe", ou seja, de que "a utilização clínica dos produtos é muito precoce, e não tem nenhum respaldo científico a favor". As associações de classe relevantes também iam tomando posição e as providências para explicitá-las não apenas para seus respectivos membros, como também para os elaboradores de política.

A SSESP, através do Grupo de Atenção à Nutrição (GAN), do Centro de Apoio ao Desenvolvimento de Assistência Integral à Saúde (Cadais), fez uma avaliação da utilização da AA, "mais especificamente a 'multimistura', que vem sendo difundida pela Pastoral da Criança, contando com o apoio do Ministério da Saúde". O documento elaborado pelo GAN questionava todos os aspectos da MM como alimento próprio para consumo.

Em novembro de 1994, o Comitê de Nutrologia da SBP, em sua reunião anual, 'analisou e aprovou' o IT dos pesquisadores da Unicamp, "no qual é apresentada e cientificamente discutida a questão da AA". O comitê publicou no Jornal de Nutrição Infantil - que tem como editor científico o dr. Fabio Ancona Lopez, atual presidente do Comitê de Nutrologia da SBP - a "tomada oficial de posição" da sociedade, assim como o texto integral do IT.

A posição da Sociedade Brasileira de Alimentação e Nutrição (Sban), a mesma adotada pela SBP, emanou de um workshop realizado em maio de 1995, em São Paulo, intitulado 'Recuperação nutricional de grupos populacionais de baixa renda: análise crítica'. Cópias das conclusões do workshop foram enviadas ao ministro da Saúde, ao secretário de Vigilância Sanitária do Ministério da Saúde (MS), ao Conselho Nacional dos Direitos da Criança e do Adolescente (Conanda) e à coordenadora do Programa Comunidade Solidária. Após listar as organizações e os pesquisadores que participaram da reunião, legitimando o documento apresentado, relatava sua estranheza com relação ao apoio que o MS, através do Inan, 'continuava' dando ao uso 
de "alimentos ditos alternativos" nos programas de intervenção nutricional para a população carente.

O relatório referia-se também ao documento 'Conclusões do grupo de trabalho sobre alimentação alternativa', assinado pelo Inan, Comin, MS, Opas e Unicef, e que colocava claramente, com relação àqueles alimentos, a necessidade de registro na Vigilância Sanitária, a necessidade da realização de mais 'pesquisas científicas' que esclarecessem as questões polêmicas em torno do assunto, e afirmava que o teor de cálcio na dieta não era bom indicativo da utilização pelo organismo etc. $O$ documento terminava ressaltando que "(a) comunidade acadêmica e as sociedades científicas não poderiam deixar de se manifestar ... realizando o seminário e divulgando amplamente nacional e internacionalmente seus resultados (reivindicando ainda) um espaço permanente junto às instituições governamentais e não-governamentais". Com essa participação, poder-se-ia estabelecer "adequadamente, o quanto do resultado destes programas (de AA) é devido às ações de promoção social desenvolvidas ou simplesmente à suplementação com esse tipo de alimento ..., sem correr o risco potencial de acreditar em medidas que passam a ser estimadas e estimuladas sem que tenham sofrido a indispensável comprovação científica da sua eficácia" (Escola Paulista de Medicina, 1995, p. 7, grifo dos autores).

Três meses após a reunião, em outubro de 1995, a Pastoral da Criança, com o "objetivo de discutir opções para a melhoria alimentar e nutricional da população, com a participação efetiva da comunidade e utilização de recursos locais", convocou um grupo de profissionais da área de saúde e nutrição de diversas instituições nacionais e internacionais. A "discussão das evidências científicas existentes sobre a MM e alimentos em uso no Brasil e outros países, assim como a necessidade de pesquisas nessa área" era um dos temas constantes da proposta de trabalho. Os outros quatro temas propostos referiam-se à discussão de estratégias para a expansão do programa de utilização de AA.

O documento final elaborado por esse grupo de trabalho, não obstante a generalidade de suas recomendações, apresentava uma conclusão - relativa ao item 'Evidências científicas e necessidade de novas pesquisas' - prontamente incorporada ao discurso da Pastoral da Criança e do Inan. O presidente do Inan fez circular uma carta, amplamente divulgada, na qual comunicava a participação do instituto no grupo de trabalho (GT), reiterando que

os respeitados profissionais e pesquisadores (que participaram do GT) concluíram que o uso da MM ... tem sido amplamente difundido no país, especialmente em grupos vulneráveis, como crianças em fase de desmame e que ainda que nem todos os aspectos quanto à biodisponibilidade de nutrientes e eventuais riscos de contaminação estejam totalmente esclarecidos, o conjunto de evidências obtidas 
até o momento sinaliza para a validade e segurança de seu emprego empopulações (Inan/MS, 1995, grifo dos autores).

A Pastoral da Criança encaminhou a várias pessoas e instituições um ofício com uma cópia do parecer do Conanda sobre o documento elaborado no workshop encabeçado pela Sban. O Conanda (Pastoral da Criança, 1996) fazia observações empíricas sobre os excelentes resultados da utilização da AA e solicitava que os organismos signatários do documento aprofundassem "a análise das bases que fundamentaram o seu parecer", questionando, a seguir, a validade científica dos trabalhos e, implicitamente, a ética na elaboração das conclusões. Questionava a rigidez da comunidade científica no tratamento da matéria, além da tentativa de transposição sem reservas dos resultados obtidos nos ensaios biológicos com ratos para a condição humana.

Das associações de classe envolvidas na controvérsia, o CFN teve papel preponderante no debate. No entanto, segundo a presidente do CFN, desde o final da década de 1980, alguns conselhos regionais, ou mesmo associados individuais, "vinham solicitando um pronunciamento oficial da entidade ..., que levou oito anos para manifestar-se, pois cobrava dos filiados que trouxessem subsídios, resultados de trabalhos (que estivessem) sendo realizados em universidades" (CFN, 1996a). O elemento para que o CFN se manifestasse publicamente, no entanto, foi o IT. Acatando "in totum o parecer dos pesquisadores da Unicamp, o CFN encaminhou cópia do IT a todos os seus conselhos regionais, para que o divulgassem", continuando, entretanto, a aguardar "resultados de pesquisas que envolvessem a MM, com o objetivo de levantar subsídios científicos que viessem a comprovar ou não a eficácia da MM no combate à desnutrição".

Mesmo concordando com a utilização integral, "dentro das práticas culinárias tradicionais e regionais, dos vegetais como contribuição para a melhoria do aporte vitamínico, mineral e de fibra vegetal", o CFN (1996a) questionava o ajuntamento de "farelos, folhas e sementes, torrando-os para se transformarem num pó miraculoso, chamado de multimistura ... (para matar) a fome e a desnutrição de nossas crianças". Ele recomendava aos "nutricionistas de todo o Brasil que se mantenham alerta para os trabalhos científicos sobre o assunto 'alimentação alternativa' ou 'multimisturas', a fim de que possam, sempre que necessário, se posicionar corretamente sobre o assunto, não infringindo, assim, o seu próprio Código de Ética”. Os conselhos regionais de Nutricionistas também deram continuidade ao processo de debate e divulgação da posição do CFN.

As críticas do Conselho Federal de Nutricionistas com relação ao apoio do Inan à utilização da MM extrapolavam a questão da alimentação alternativa, evidenciando a existência de uma divergência 
na forma como as instituições entendiam que os problemas de fome e desnutrição no Brasil deviam ser abordados. Para o CFN, o Inan ainda estava por estabelecer uma política nacional de alimentação e vinha tendo dificuldades em abordar os problemas de alimentação e nutrição no Brasil de maneira efetiva.

O CFN intensificou a campanha de 'esclarecimento' entre seus afiliados, incluindo a punição por parte do conselho daqueles profissionais que não obedecessem às suas diretrizes de "não envolvimento, promoção ou concordância com a utilização da MM e do FA". Assim, a determinação e o posicionamento do CFN com relação ao uso da MM acabou sendo um divisor de águas na disputa, pelo menos no que concerne aos profissionais da área de nutrição. Vários deles - por nós entrevistados — foram categóricos ao afirmar que a decisão do CFN os tinha feito recuar da preconização do uso da MM como parte de suas atividades.

Também os leigos envolvidos com os programas de combate à fome, alertados sobre o debate pelas freqüentes publicações na mídia, em todo país, manifestaram preocupação com relação à continuidade do uso da MM. Um frade escreveu, em 1995, ao dr. Nelson Arns Neumann, da Coordenação Nacional da Pastoral da Criança, transmitindo a preocupação dos membros atuantes de sua comunidade que trabalhavam com ações de atendimento às mães "com a orientação divulgada pela imprensa de São Paulo e local da nova descoberta e de novas propostas alimentares feitas por doutores da Unicamp, (que) sugerem a abolição da MM por não ser cientificamente provado seu valor". "Por outro lado", esclarecia o frade, "a Rede Alternativa contra a Fome questiona duramente a tese dos doutores e doutorandos acima citados e diz que lhes falta seriedade e competência", e ele pedia a orientação da Coordenação Nacional da Pastoral da Criança sobre como proceder (Pires, 1995).

Um médico de Andradas, Minas Gerais, escreveu ao Jornal de Pediatria, perguntando a respeito de resultados de trabalhos sobre a utilização da MM como alimento complementar em crianças menores de dois anos de idade (Pontes, 1996). A resposta, elaborada pelo dr. Naylor A. L. de Oliveira (1996), então presidente do Comitê de Nutrologia da SBP, fazia referência a Torin e seus colaboradores e dizia que o Comitê de Nutrologia da SBP "não indica os farelos como fonte segura de minerais para ser utilizada na recuperação nutricional dos desnutridos". O médico mineiro, a despeito dos "ótimos resultados" obtidos com o uso da MM, suspendeu o fornecimento desse produto em seu programa de recuperação de desnutridos.

Algumas secretarias de Saúde criaram grupos de trabalho para, à luz de todo esse debate, "avaliar a utilização e eficácia do uso de AA". Depois de examinar "amplamente" o "material bibliográfico existente a nível nacional", o GT criado pelo secretário de Saúde do 
${ }^{5}$ Estamos aqui circunscritos às evidências apresentadas por uma ou ambas as partes durante o debate.
Distrito Federal chegou às seguintes conclusões: "pela suspensão do uso do Fa e do Ft como suplemento alimentar para seres humanos, pelo seu altíssimo conteúdo de ácido fítico, que interfere na absorção de $\mathrm{Zn}, \mathrm{Fe}, \mathrm{Mg}$ e Ca; suspender o pó da folha de mandioca ... pelo alto teor de ácido cianídrico; o uso do pó da Co é precoce ... quanto à biodisponibilidade do cálcio" (GDF/SES, 1995, pp. 2-3)

Assim, as ações por parte de algumas associações de classe, como a SBP, através do seu comitê de nutrologia, a Sban e particularmente o CFN têm confrontado as ações de combate à desnutrição que utilizam AA, conseguindo, em alguns casos, pela pressão corporativa e ameaças de cumprimento do regulamento, reverter a tendência ao uso dos produtos. As instituições têm se respaldado de maneira substantiva nas "evidências científicas" dos trabalhos de Torin e Nogara, e, mais concretamente, vêm buscando legitimação no IT elaborado por pesquisadores que, mais do que suas respectivas competências individuais, têm como lastro uma instituição como a Unicamp.

\section{Discussão}

Sou tecnicamente contra o uso do farelo de arroz como suplemento alimentar e politicamente contra o uso da multimistura como alimento alternativo (Domene, 1996a).

A controvérsia aqui analisada, face à exiguidade de dados experimentais, acaba tendo sua tônica deslocada para o uso de apenas um produto, o Fa, único entre todos os outros a ser objeto de experimentação científica, ${ }^{5}$ que pretendia avaliar sua efetividade como alimento alternativo. Mesmo no caso do $\mathrm{Fa}$, os dados disponíveis para uma avaliação conclusiva de sua efetividade como nutriente (ou antinutriente) são escassos. No entanto, pode-se perceber, da parte dos profissionais ligados à área de nutrição, um inequívoco alinhamento de tendências contra ou a favor da 'causa' da AA.

A controvérsia e a tomada de posição dos contendores acabam por definir com clareza dois grupos: o primeiro, dos proponentes, tem na Pastoral da Criança o maior promotor da idéia da AA — até mesmo pelo volume de crianças que atendem utilizando esse tipo de alimento. Também é notória a participação do Inan/MS nesse grupo, senão como instituição, pelo menos na pessoa da médica Clara Takaki Brandão. A visibilidade e a credibilidade conferidas a ela, pela posição que ocupa no Inan, são indiscutíveis

Ao mesmo tempo, os pesquisadores da Faculdade de Engenharia de Alimentos da Unicamp e da Puccamp sentiram-se confortáveis para elaborar o IT, com o qual pretendiam dividir com seus pares e alguns elaboradores de política os conhecimentos adquiridos em suas 
pesquisas sobre o Fa como nutriente. A oposição institucional à adoção da AA vinha sendo organizada basicamente em torno do CFN e de seus conselhos regionais. No entanto, a 'legitimação técnica' para a construção de uma agenda de oposição sistemática ao uso da MM foi fornecida pelos trabalhos de Amaya-Farfán e seus colaboradores.

O presidente do Inan à época do lançamento do IT, o dr. Carlos Alberto Guimarães, recebeu, juntamente com o informe, uma correspondência "inquirindo sobre a posição oficial do Inan com relação à orientação alimentar à população brasileira para o consumo de alguns alimentos não convencionais". Na resposta, ele referiu-se ao documento elaborado pelo grupo de trabalho sobre AA, citando o elenco de suas recomendações, as quais o Inan estaria acatando integralmente, e esclarecendo ainda que, "por determinação da Secretaria Executiva do Ministério da Saúde, a dra. Clara Brandão passou a colaborar com o Inan a partir de outubro de 1994, com a orientação específica de encaminhar o desenvolvimento dos estudos e pesquisas recomendados pelo grupo de trabalho" (Inan/MS, 1994). A resposta concluía afirmando que o MS e o Inan só poderiam "emitir posição oficial sobre o uso dos farelos de trigo e arroz e do pó da folha de mandioca para a recuperação nutricional após conclusão de todos os estudos recomendados pelo grupo de trabalho" (idem, ibidem, p. 3).

Nossas tentativas de explicar as diferenças de interpretação e, portanto, de posicionamento sobre a efetividade da alimentação alternativa, estão mais centradas em fatores ideológicos, políticos e talvez comerciais, que procuram utilizar como base de sustentação um arrazoado de cunho científico. $\mathrm{Na}$ busca de um entendimento desse processo de negociação social, a primeira questão que nos ocorre é a radicalização na interpretação de dados ainda escassos, sobre a efetividade do alimento alternativo, na nutrição infantil: como podem cientistas trabalhando sob as mesmas condições divergirem tão radicalmente na interpretação dos dados e resultados experimentais?

Com efeito, ainda não existem evidências empíricas conclusivas que demonstrem a efetividade e os riscos da utilização do Fa como dieta recuperativa de crianças. No entanto, para McCrea et al. (1984, p. 15), nesse tipo de controvérsia "o alinhamento de grupos é freqüentemente baseado em fatores situacionais, mais do que nos fatores científicos. Esse alinhamento sempre ocorre primeiro, e apenas depois disso, os novos partidários da idéia constroem a racionalidade para seu alinhamento."

A situação de oposição a priori é clara no caso do CFN, que em 1990 se manifestou publicamente com relação à Cartilha de AA elaborada pela dra. Brandão, sob o patrocínio da FBB. Na época, sem a 'racionalidade' fornecida mais tarde pelos trabalhos de Torin et al. (1994; 1993), o documento do CFN restringia-se a tecnicalidades do 
${ }^{6}$ Quanto à utilização da Co em pó como fonte de cálcio e das Fm em dietas, os cientistas, introduzem o princípio da incerteza no debate. Isso poderia nos levar a supor que, caso tivéssemos mais 'informações' sobre a real disponibilidade de Ca na casca de ovo processada, sobre os reais efeitos do HCN sobre a saúde das pessoas, ou, ainda, sobre os modos seguros de reduzir os níveis de HCN na Fm processada, os desacordos sobre a validade de sua utilização desapareceriam. documento, sem se posicionar radicalmente contrário à prática, o que viria a ocorrer alguns anos mais tarde.

Embora sejam várias as questões técnicas (e outras de ordem moral e ética) indicadas pelos oponentes da MM, a questão dos antinutrientes, e particularmente dos fitatos, acabaram tornando-se o nó górdio de toda a controvérsia sobre a utilização do $\mathrm{Fa}$ e assemelhados. Grosso modo, o Fa poderia, de acordo com os resultados das pesquisas desenvolvidas (ou citadas) pelos oponentes, atribuir à AA características exatamente opostas à finalidade almejada pelos proponentes de sua utilização. Ainda que os outros componentes da $\mathrm{MM}$, como $\mathrm{Fm}$ e $\mathrm{Co}^{6}$ fossem igualmente relevantes, foi o ácido fítico que suscitou as principais discordâncias, o que indica a necessidade de um maior esclarecimento sobre ele, para entendermos melhor o debate em seus fundamentos técnicos.

O ácido fítico, ou hexafosfato de mio-inositol (IP6), representa de 1 a $2 \%$ em peso de grãos integrais, podendo em alguns casos atingir até 5\%, como o caso da semente do gergelim. Ele pode ocorrer também em outras formas, que são os precursores metabólicos fosforilados do IP6, que vão desde o IP5 (o pentafosfato) até o IP1, o monofosfato de mio-inositol. Pela capacidade de ligação a minerais e proteínas, o ácido fítico pode interferir sobre as propriedades funcionais e nutricionais dos alimentos. Embora alegue-se que as formas de maior poder complexante sejam IP6, IP5 e IP4, não se descarta a possibilidade de as outras formas existentes possuírem poder ligante de intensidade variável.

Para os oponentes da AA, não existem dúvidas sobre a ação do ácido fítico sobre a biodisponibilidade dos minerais e, por conseguinte, do alto teor daquele ácido no Fa: "a adoção do farelo de arroz como fonte mineral para alimentação humana não se apresenta como uma perspectiva segura" (Domene, 1996b, p. 76).

Entretanto, de acordo com a médica Rebeca de Angelis, professora do Laboratório de Fisiologia da Universidade de São Paulo (USP) e simpatizante do programa de AA, apesar de se estar colocando como grande problema na utilização de minerais, "a presença de fitatos nos farelos não é relevante do ponto de vista nutricional". Diz ela (Angelis, 1996, p. 2, grifo no original):

Cereais e leguminosas amplamente consumidos por nossa população contêm altos teores de fitato e de polifenóis, além de fibras que poderiam inibir a bioutilização de certos minerais como cálcio e zinco, entre outros nutrientes. Pois bem, ocorre que a nossa população vive bem há muito tempo, mesmo comendo diariamente arroz e feijão. É que existe o que se chama de adaptação fisiológica. Os indivíduos que consomem sempre esses alimentos passam a se adaptar às condições e absorvem quantidades adequadas de nutrientes, mesmo comendo bastante fitatos, fibras. Entretanto, para populações que não têm o hábito de ingerir esse 
tipo de alimentos, (eles) apresentam uma grande inibição da absorção intestinal.

A dra. Domene (1996, pp. 15-75), entretanto, não aceitou a explicação da adaptação fisiológica: "a noção de que as fitases endógenas possam contribuir para a digestibilidade do ácido fítico não tem comprovação científica", sendo que a evidência empírica disso seria dada pelos

estudos (que) apontam que a presença deste fator antinutricional é responsável pela baixa ... qualidade de dietas consumidas por populações que têm nos grãos a base de sua alimentação, como as paquistanesas, que, mesmo vivendo na Noruega, mantêm seus hábitos alimentares e apresentam uma incidência de 68\% de anemia, contra $17 \%$ observada em não paquistanesas no mesmo país.

$\mathrm{Na}$ perspectiva do grupo de proponentes, tanto Angelis (1996) quanto Camara (1996) alegavam que o processamento dos fitatos a altas temperaturas faz com que eles percam alguns radicais fosfatos, diminuindo-se, assim, sua ação inibidora na absorção de minerais. Na mesma linha de argumentação, Maffei (1996) entendia que os trabalhos de Torin et al. exacerbavam a questão da biodisponibilidade, por utilizarem apenas um dos componentes da MM, ou seja, o Fa, e em uma "concentração absolutamente não fisiológica ... muito alta, e que nessa situação a falta de biodisponibilidade passa a ser bem evidente. Porém, isso não reproduz a situação que está sendo colocada para a MM, numa concentração menor de farelo, situação em que o teor de fitatos" não chegava a representar problema.

Os proponentes da AA não desconheciam os efeitos complexantes de minerais do ácido fítico contido no Fa. No entanto, para eles, esses efeitos estavam exagerados nos experimentos realizados por Torin et al. e por Nogara. Angelis (1996, p. 1), por exemplo, partia da premissa de que toda conduta contrária ao emprego da MM era derivada sobretudo dos experimentos de Torin (1992) e Nogara (1994), mas que os experimentos não haviam sido conduzidos com o rigor científico desejado: "os trabalhos não foram felizes no protocolo (utilizado)", sendo que, para o caso de Torin, "foi colocada na dieta uma quantidade excessiva do farelo de arroz, fornecendo quantidade elevada de fibra e de fitato". No caso de Nogara, que não encontrou resultados benéficos, "os experimentos foram também mal protocolados, pois estudaram crianças normais (e não as desnutridas)".

O questionamento da qualidade dos trabalhos científicos desenvolvidos pelos oponentes da MM era uma constante entre os proponentes do uso da MM enriquecida com farelo. As críticas concentravam-se em dois aspectos daqueles trabalhos: a questão do protocolo utilizado, como, por exemplo, a quantidade excessiva de farelo, a incomensurabilidade de comparação entre ratos e humanos, 
7 O documento foi obtido sob condição de sigilo e encontra-se em poder dos autores para consulta, sem autorização para divulgação. o estado nutricional e/ou a idade adequados para checar-se o resultado da recuperação nutricional etc.; e a excessiva importância atribuída aos agentes quelantes sobre a fração mineral dos alimentos.

Uma pesquisadora da área de nutrição da Universidade de Brasília (UnB) fez uma avaliação da tese de doutoramento de Torin, concluindo que: "o trabalho de pesquisa é de muito baixo mérito ... com uma introdução muito fraca, só aceitável para um trabalho de iniciação científica ... tendo sido utilizado rato albino (Wistar) que já é um mutante artificialmente obtido e certamente apresenta grandes alterações metabólicas em relação ao rato comum. Daí a transpor os dados para humano é um grande exagero..." ${ }^{\prime}$ Apesar da pouca experimentação científica desenvolvida no sentido de se testar "objetivamente" o valor nutricional e recuperativo da alimentação alternativa, ficavam claras as dificuldades de se encontrarem os denominadores comuns não apenas no delineamento do experimento.

Essa rodada de negociação social encerrou-se com a realização da X Conferência Nacional de Saúde, realizada pelo Ministério da Saúde em Brasilia, em 1996. Nela, os opositores da AA prepararam uma moção a ser encaminhada à mesa, que dizia o seguinte:

Que a solução para a fome se dê através de mudanças estruturais e não de distribuição de triturados de subprodutos de alimentos, preservando-se os princípios de justiça, responsabilidade, tolerância e pluralidade que norteiam a bioética. Que para o atendimento das necessidades imediatas, decorrentes da fome, se utilizem em programas emergenciais, especialmente, os viabilizados pelo SUS, produtos alimentares comuns à mesa do brasileiro. Que qualquer outra forma de alimentação proposta pelas esferas de governo e/ou segmentos da sociedade civil, como alternativa de intervenção, sejam amplamente discutidas e deliberadas nos conselhos distritais e municipais de Saúde. Neste caso, parcerias entre as universidades e o poder público municipal e estadual devem viabilizar análises de composição de alimentos, combinados ou não, para imediata divulgação de seu valor nutricional e fundamentação dos conselhos de Saúde.

Do outro lado da barricada, segundo relato de uma das autoras, os proponentes da AA elaboraram sua moção com o seguinte teor:

Os participantes da X Conferência Nacional de Saúde reconhecem os trabalhos da Pastoral da Criança como úteis e fundamentais no desenvolvimento de comunidades carentes e no acesso à cidadania, inclusive reconhecem a prática do uso de alternativas alimentares (multimistura) como ação básica de saúde, de grande importância na recuperação de desnutrição e na prevenção deste agravo de saúde, como vem demonstrando a longa experiência empírica daquela instituição e um número crescente de trabalhos científicos recentemente desenvolvidos. 
$\mathrm{Na}$ fase de coleta de assinaturas para o encaminhamento das moções à mesa diretora, foi feita uma negociação entre as partes (oponentes e proponentes da AA), e nenhuma das duas moções foi encaminhada. Isso evitou um confronto político entre as duas partes, que ainda hoje continuam buscando evidências 'técnicas' que comprovem a validade das respectivas argumentações.

\section{Conclusão}

Na década de 1980, as críticas aos programas de AA centravamse, sobretudo, na questão ideológica e mercadológica. Os críticos referiam-se a essas iniciativas como propostas de 'alimentação para pobres', alegando que a questão da fome, por ser estrutural, demandava alterações profundas na sociedade brasileira, particularmente a melhor distribuição de renda, a partir de um reordenamento da economia nacional que favorecesse uma participação mais justa de todas as classes sociais no eventual crescimento econômico do país.

Com relação aos aspectos mercadológicos, inquiria-se sobre os baixos preços dos produtos utilizados na elaboração da AA, alegando-se que, caso o programa fosse exitoso, a demanda por esses produtos promoveria reajustes de mercado, fatalmente causando aumento de preços, à semelhança dos produtos industrializados. As próprias necessidades de se adequar a qualidade desses produtos às exigências da Vigilância Sanitária para efeitos de inspeção e fiscalização sanitária provocariam o aumento dos preços.

Embora essas questões sejam tangencialmente abordadas nas críticas mais recentes aos programas de AA, a partir das pesquisas de Torin (1991) e Nogara (1994), o eixo das críticas ao programa desloca-se, passando a focalizar questões categorizadas como técnico-científicas. O problema da biodisponibilidade, com maior ênfase na questão do ácido fítico como complexante de minerais, acaba sendo identificado e aclamado pela comunidade científica de opositores como a evidência incontestável da ineficácia e dos riscos da AA preconizada pela Pastoral da Criança e pela médica Clara Brandão.

Para as instituições críticas da AA como dieta recuperativa de desnutridos, como Conselho Federal de Nutricionistas, Grupo de Atenção à Nutrição, Centro de Apoio ao Desenvolvimento de Assistência Integral à Saúde, Sociedade Brasileira de Alimentação e Nutrição, Sociedade Brasileira de Ciência e Tecnologia de Alimentos etc., os resultados das pesquisas de Torin, Domene e Nogara forneciam, portanto sem muito questionamento sobre méritos e procedimentos da pesquisa -, legitimidade científica. A validade dos resultados e a competência dos pesquisadores acabam sendo secundárias nesse contexto, à medida que as descobertas vinham reforçar sobremaneira a posição dos críticos. Essa atitude não é inesperada em uma 
${ }^{8}$ No Jornal Nacional, da TV Globo, no Aqui e Agora, do SBT, e em reportagem de capa da revista Veja, (jan. 1997) controvérsia como a que discutimos. Nesse sentido, Nelkin (1975, pp. 51-2), em sua análise sobre o impacto político dos técnicos especialistas, conclui que "a aceitação de um aconselhamento técnico depende mais de como ele reforça as posições existentes do que da sua validade e da competência dos expertos que o formularam".

A dimensão política da prática da AA, tal como proposta pela Pastoral da Criança e pela dra. Brandão, parece não ter sido adequadamente entendida pela Academia, que, ingenuamente ou não, busca salientar alguns eventuais efeitos colaterais do uso da MM, apoiando-se em evidências fornecidas por experimentações científicas ainda inconclusivas. Essas são atitudes corporativas previsíveis dentro da comunidade científica, para a qual, segundo Mooney (1983, p. 65), "O mundo consiste de cientistas e de não-cientistas, (e o que) para cientistas pode parecer um grito primevo, para os não-cientistas pode não passar de uma tosse acadêmica".

Por outro lado, não é evidente o papel recuperativo da AA per si. Parece ser mais razoável entender os efeitos dessa alimentação em um contexto mais amplo de integração mãe/criança, além das ações básicas de saúde carreadas com a preconização do uso da MM (Naibo, 1996). Essa estratégia já era adotada pela dra. Brandão no caso das creches Seara, em Santarém, e posteriormente disseminadas por todo território nacional pela Pastoral da Criança.

Outro aspecto que chama atenção no debate - e que mereceria ser melhor explorado do ponto de vista sociológico em futuras pesquisas - é o papel que a mídia tem desempenhado na promoção da controvérsia. Um exemplo que dimensiona a importância desse papel é o fato de que tenham aparecido, concentradas nas duas últimas semanas de janeiro de 1997, em duas das maiores redes de televisão do país, em horário nobre, e em uma revista semanal de circulação nacional, ${ }^{8}$ reportagens sobre os "excelentes resultados" alcançados pela Pastoral da Criança no combate à fome, com o uso da MM. Isso mostra que as convicções e os objetivos dos preconizadores da utilização da MM estão longe de terem sido abalados.

Por outro lado, talvez como resultado da seletividade da mídia, a simples aparição do tema no horário nobre e o destaque que recebeu "legitimam o assunto como candidato à atenção política, além de aumentar (ainda mais) sua prioridade na agenda política" (Goodell, 1987, pp. 585-6). É importante ressaltar que estava sendo veiculado nessas matérias não apenas o antigo e eterno problema da fome, mas também uma nova solução para ele: a MM ou, de acordo com algumas nutricionistas do CFN, o "pozinho mágico de pirlimpimpim".

Pode-se concluir preliminarmente que essa controvérsia adquire contornos que a caracterizam mais como uma luta política entre aqueles que acreditam estar amenizando o problema da fome com propostas alternativas que não dependem necessariamente das 'reformas estruturais profundas' da sociedade — que ainda custarão a ocorrer 
—, e os que acreditam que esses paliativos só perpetuam o estado de miséria e desnutrição de boa parcela do povo brasileiro.

As poucas tentativas, até aqui, de investigar 'cientificamente' a efetividade da AA, mais particularmente do Fa como alimento alternativo, apesar do esforço de seus autores em mostrar desinteresse e objetividade nas pesquisas, acabaram demonstrando-se problemáticas particularmente da perspectiva dos proponentes da AA - , no sentido de não atenderem ao que era efetivamente proposto como 'dosagens ideais' dos produtos testados. Isso vem corroborar descobertas similares nas análises de controvérsias da área médica, quando se conclui que "avaliação terapêutica é inerentemente um processo social e político, e que a idéia de uma avaliação neutra é um mito", que "a avaliação da terapia médica não pode ser feita isoladamente dos interesses e objetivos sociais que permeiam essas terapias" (Richards, 1988, p. 685).

Vale lembrar que os julgamentos sobre os resultados obtidos experimentalmente são condicionados pelos valores e interesses profissionais da comunidade envolvida, seja essa comunidade científica, religiosa, ONG etc. Além disso, a leitura e a interpretação de tais resultados podem ser condicionados por interesses sociais mais amplos ou prementes, tais como as forças do mercado, a liberdade de escolha do consumidor, ou, ainda, como no nosso caso, a falta de liberdade de escolha do consumidor da multimistura.

\section{REFERÊNCIAS BIBLIOGRÁFICAS}

Abraham, J. 1993

Alencar, Marcelo. L.; Brandão, Clara T. e Alvarenga, N. G. mar. 1991

Allen, Garland E. 1987

Amaya-Farfán, Jaime 1996

Angelis, R. C. de 1996

Beausset, I. 1992

Brandão, Clara T. jul. 1996

Brandão, Clara T. 1994
Social Studies of Science, vol. 23, pp. 387-444.

'Farelo de arroz: composição química e seu potencial como alimento'. Arquivos de Biologia e Tecnolologia, 34(1), pp. 95-108.

'The role of experts in scientific controversy'.

Em Tristam H. Engelhardt e Arthur Caplan (orgs.), Scientific controversies. Londres, Cambridge University Press, pp. 169-202.

Entrevista concedida aos autores, na Unicamp, em 28 de maio.

'Considerações sobre a multimistura: reflexões'. Documento apresentado na Comissão Intersetorial de Alimentação e Nutrição do Conselho Nacional de Saúde. Brasília. (mimeo.)

'Estudio de las bases cientificas para el uso de alimentos alternativos en la nutricion humana'. Brasília, Inan/Unicef. (mimeo.)

Entrevista concedida aos autores na sede do Inan/Brasília.

Alimentação e saúde.

$9^{\underline{a}}$ ed., Brasília, CNBB/Pastoral da Criança. 

1989

Brandão, Clara T. et al. $1983 \mathrm{a}$ Secretaria Nacional de Ações Básicas de Saúde do Ministério de Saúde.

(1)

'Combate à desnutrição em Santarém: resultados após três anos de trabalhos intensivos'. Artigo apresentado no XXIII Congresso Brasileiro de Pediatria. Salvador, 2 a 9 de setembro de 1983.

Brandão, Clara T. et al. $1983 \mathrm{~b}$

Brandão, Clara T. et al.

Brandão, Clara T. et al.

'A recuperação do desnutrido através da educação familiar'.

Artigo apresentado no XXIII Congresso Brasileiro de Pediatria.

'Programa de cuidados primários de saúde em Santarém — Pará'. Artigo apresentado no XXIII Congresso Brasileiro de Pediatria. $1983 \mathrm{~d}$

'Programa de nutrição em Santarém - Pará'.

Artigo apresentado no XXIII Congresso Brasileiro de Pediatria.

Brandão, Clara T. et al. $1983 \mathrm{e}$

'Obstipação por correção de imperfuração anal: solução regional'. Artigo apresentado no XXIII Congresso Brasileiro de Pediatria.

Brandão, Clara T. et al. $1983 \mathrm{f}$

Camara, F. S. 1996

Campbell, B. L. 1985

CFN/Conselho

Federal de Nutricionistas 1996a

CFN/Conselho

Federal de Nutricionistas 1996b

CNBB/Pastoral da Criança mar.-abr. 1996

Del Sesto, Steven L. 1983

Domene, Semiramis

M. A. $1966 \mathrm{a}$

Domene, Semiramis M. A.

1996b

Domene, Semiramis M. A. et al.

1994

Dutra de Oliveira, José P.

1994

Escola Paulista de Medicina

Faculdade de Ciências Médicas/Puccamp 1994

Fundação Banco do Brasil

1996

'Atenção primária de saúde através do programa Criança para Criança'. Artigo apresentado no XXIII Congresso Brasileiro de Pediatria.

'Fome oculta: fitatos'. Palestra proferida no I Congresso Nordestino de Qualidade de Vida e Práticas Alimentares. Fortaleza, 10 a 12 de junho.

'Uncertainty as symbolic action in disputes among experts'. Social Studies of Science, vol. 15, pp. 429-53.

'Posicionamento do CFN quanto à multimistura', 5 de fevereiro. (mimeo.)

Entrevista com Maria Helena Vilar e Vera em 29 de julho.

'Situação de abrangência: $4^{\circ}$ trimestre de 1995'.

Jornal Pastoral da Criança, ano XII, n⿳ํㅡㄹ 39, p. 2.

'Uses of knowledge and values in technical controversies: the case of nuclear reactor safety in the US'. Social Studies of Sciences, vol. 13, pp. 395-416.

Entrevista concedida aos autores na Faculdade de Ciências Médicas da Pontifícia Universidade Católica da Campinas, Campinas.

Estudo do valor nutritivo mineral do farelo de arroz: utilização do zinco, ferro, cobre e cálcio pelo rato em crescimento. Tese de doutoramento, Campinas, Faculdade de Engenharia de Alimentos da Unicamp.

'Alimentação com farelo de arroz e deposição de zinco no fígado de rato'. Trabalho apresentado ao X Encuentro Latinoamericano de Nutrición da Sociedade Latinoamericana de Alimentacion y Nutrición. Caracas.

Correspondência ao Departamento de Planejamento Alimentar e Nutrição da Unicamp.

'Recuperação nutricional de grupos populacionais de baixa renda: análise crítica'. Relatório do workshop realizado em 5 de maio.

Posição oficial da FCM/Puccamp sobre a CC № 04/95-P/Inan-BSB.

\section{Alimentação alternativa.} Brasília. 


$\begin{aligned} & \text { Fundação Banco } \\ & \text { do Brasil } \\ & 1993 \\ & \text { GDF/SES } \\ & 1995 \\ & \text { Giere, Ronald N. } \\ & 1987\end{aligned}$
Gillespie, B. et alii
1979
Gondim, Enise
M. G. et al.
1995
Goodell, Rae
1987

10.11.1995

14. 12.1994

1992

6. 11. 1994

Jornal de Nutrição

Infantil

1995

Maffei, $\mathrm{H}$.

Markle, G. E. e

Petersen, J. C. Spring 1981

Martin, Brian

1988

Mazur, Allan

1987

Mazur, Allan

1981

Mazur, Allan

McCrea, F. B. e

Markle, G. E.

1984

McMullin, E. 1987

Ministério da Saúde $1994 a$
Alimentação alternativa.

Brasília, 68p.

Grupo de trabalho sobre alimentação alternativa do Distrito Federal. (mimeo.)

'Controversies involving science and technology: a theoretical perspective'.

Em T. H. Engelhardt e A. Caplan (orgs.), Scientific controversies. Londres, Cambridge University Press, pp. 121-50.

'Carcinogenic risk assessment in the United States and Great Britain: the case of aldrin/dieldrin'. Social Studies of Science, vol. 9, pp. 265-301.

Os benefícios do farelo de trigo na alimentação de crianças de creche.

Monografia apresentada ao curso de especialização em Saúde Pública da Unifor. (mimeo.)

'The role of the mass media in scientific controversies'.

Em Tristam H. Engelhardt e Arthur Caplan (orgs.), Scientific controversies. Londres, Cambridge University Press, pp. 585-97.

Instituto Nacional de Alimentação e Nutrição, Ministério da Saúde. Carta Circular 04/95 — P/Inan-BSB.

Instituto Nacional de Alimentação e Nutrição, Ministério da Saúde. Ofício 389/94-p/Inan, a Hilda Torin, Semiramis Domene e Jaime Amaya-Farfán. Instituto Nacional de Alimentação e Nutrição, Ministério da Saúde. Workshop sobre suplementação alimentar com alimentos não convencionais. Brasília, 18 e 19 de fevereiro.

ISPN- International Society of Pediatric Nutrition. Correspondência encaminhada aos profesores Torin, Domene e Amaya-Farfán.

'Alimentação alternativa: posição da Sociedade Brasileira de Pediatria' (editorial). Ano II, n9, pp. 1-4.

Entrevista concedida aos autores em junho de 1996.

'Controversies in science and technology: a protocol for comparative research'. Science, Technology \& Human Values, vol. 6, nㅜ 34, pp. 25-30.

'Analysing the fluoridation controversy: resources and structures'. Social Studies of Science, vol. 18, pp. 331-63.

'Scientific disputes over policy'.

Em Tristam H. Engelhardt e Arthur Caplan (orgs.), Scientific controversies. Londres, Cambridge University Press, pp. 265-82.

The dynamics of technical controversy.

Washington, Communication Press Inc.

'Dispute between experts'.

Minerva, XI:2, pp. 245-9.

'The estrogen replacement controversy in the USA and UK: different answers to the same questions?'. Social Studies of Science, vol. 14, pp. 1-26.

'Scientific controversy and its termination'.

Em Tristam H. Engelhardt e Arthur Caplan (orgs.), Scientific controversies. Londres, Cambridge University Press, pp. 49-91.

'Conclusões do grupo de trabalho sobre alimentação alternativa'. Brasília, Instituto Nacional de Alimentação e Nutrição. (mimeo.) 


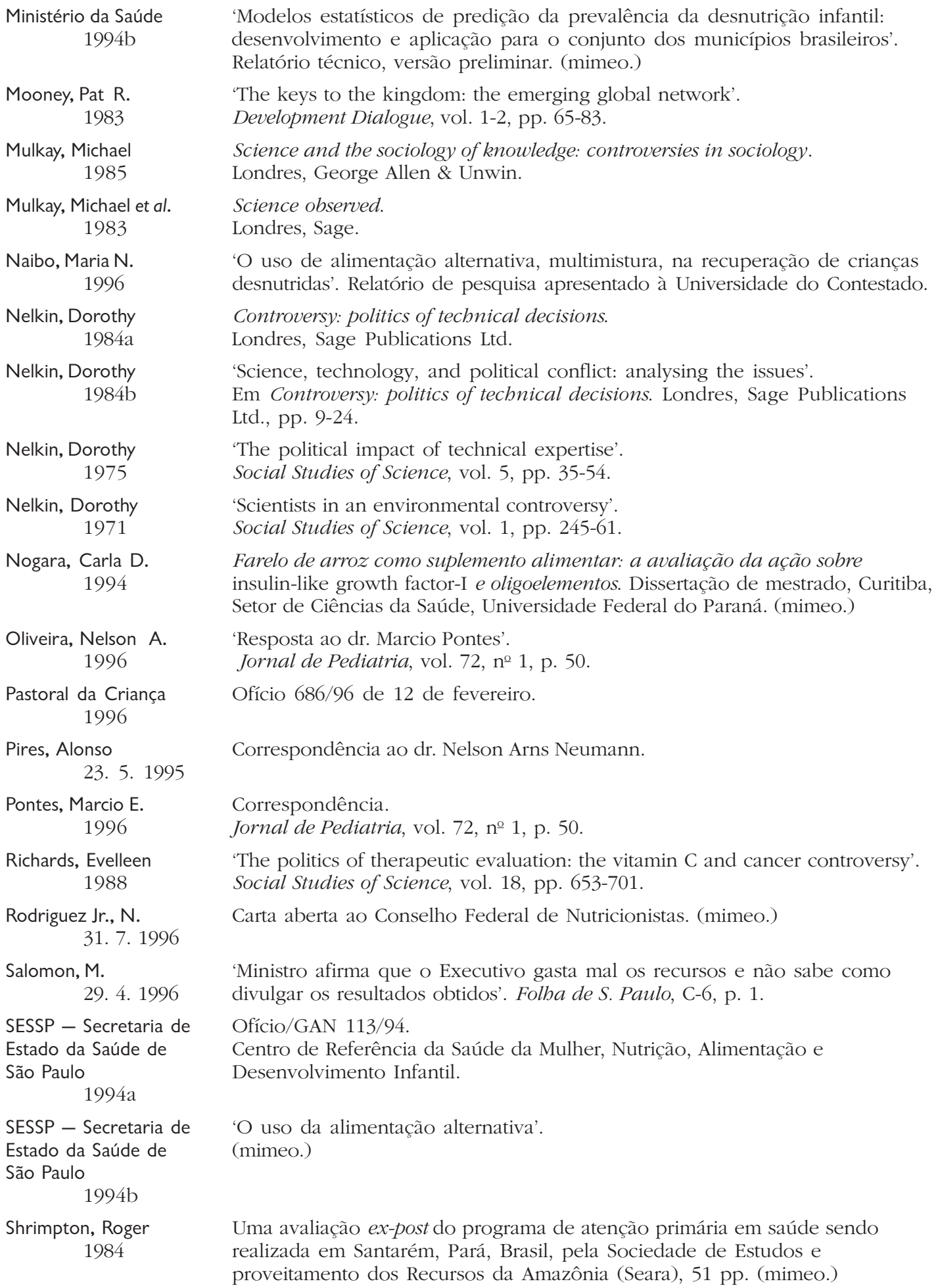
proveitamento dos Recursos da Amazônia (Seara), 51 pp. (mimeo.) 
Torin, Hilda R. 1996

Torin, Hilda R. 1994

Torin, Hilda R. July 1993

Torin, Hilda R. et al. jul. 1992

Torin, Hilda R. 1991

Trugo, Luís Carlos 1994

Unicef ago. 1994

Webster, Andrew 1991
Dietas à base de farelo de arroz: efeito na composição mineral do fêmur do rato, avaliado por processamento da imagem radiográfica.

Tese de doutoramento, Campinas, Faculdade de Engenharia de Alimentos da Unicamp. (mimeo.)

'El efecto de suplementar el salvado de arroz industrial con calcio y zinco'. Trabalho apresentado no XI Congreso de Nutrición. Santiago, Chile 28 a 30 de setembro.

'Limited bioavailability of zinc in 'Brazilian industrial rice bran'. Trabalho apresentado no XV International Congress of Nutrition em Adelaide, Austrália.

'Avaliação do valor recuperativo do farelo de arroz em ratos submetidos a depleção nutricional'. Trabalho apresenado ao X Congresso da Sociedade Brasileira de Ciência e Tecnologia de Alimentos, Rio de Janeiro.

Utilização do farelo de arroz industrial: composição e valor nutrificante em dietas recuperativas. Dissertação de mestrado, Campinas, Faculdade de Engenharia de Alimentos da Unicamp. (mimeo.)

Correspondência ao Departamento de Planejamento Alimentar e Nutrição da Unicamp.

'Alimentação alternativa, aspectos nutricionais e sociais: o papel das instituições'. Fortaleza. (mimeo.)

Science, technology and society: new directions (sociology for a changing world). Sydney, Macmillan Education Ltd.

Recebido para publicação em junho de 2000. Aprovado para publicação em agosto de 2001. 